\title{
Bilateral basal ganglia ischemia associated with COVID-19: a case report and review of the literature
}

\author{
Khurram Khaliq Bhinder ${ }^{1} \mathbb{B}$, Ahsun Rizwan Siddiqi² ${ }^{2}$, Muhammad Junaid Tahir ${ }^{3}$, Hamza Maqsood ${ }^{4 *}$, \\ Irfan Ullah ${ }^{5}$ (B) and Zohaib Yousaf ${ }^{6}$ (I)
}

\begin{abstract}
Background: Coronavirus disease 2019, caused by the severe acute respiratory syndrome coronavirus 2, has a broad clinical spectrum, from asymptomatic to multi-organ dysfunction. Acute cerebrovascular events associated with coronavirus disease 2019 are mainly due to the severe acute respiratory syndrome coronavirus 2-induced prothrombotic state. Bilateral basal ganglia ischemia is rarely reported.
\end{abstract}

Case presentation: We report the case of a 64-year-old Asian (Pakistani) gentleman who presented initially with fever, cough, and shortness of breath, likely due to respiratory involvement by severe acute respiratory syndrome coronavirus 2. Later, he developed bilateral lower limb pain, followed by confusion and decreased level of consciousness. Accentuated large hypodense opacities were seen in the left and right basal ganglia, with mass effects on the left frontal horn.

Conclusion: This case demonstrates the importance of neuroimaging in the effective management of patients with neurological signs associated with coronavirus disease 2019.

Keywords: SARS-CoV-2, Infection, Brain, Neurology, Radiology, Neuroimaging

\section{Background}

Coronavirus disease 2019 (COVID-19) results in a broad spectrum of clinical manifestations [1]. A third of the infections are symptomatic. The predominant symptoms are consistent with respiratory involvement and include fever, cough, dyspnea, and fatigue. However, a severe illness characterized by acute respiratory failure, septic shock, and multi-organ failure leading to death is also reported [1]. In addition, patients with COVID-19 are at an increased risk of developing prothrombotic complications, including deep venous thrombosis, acute limb ischemia, and ischemic stroke [2]. Studies estimate that

*Correspondence: hamzamaqsood381@gmail.com;

hamzamaqsood381@gmail.com

${ }^{4}$ Nishtar Medical University and Hospital, Multan, Pakistan

Full list of author information is available at the end of the article
0.8-6.4\% of coronavirus patients experience an ischemic infarct [3]. However, bilateral basal ganglia ischemia is rarely reported in COVID-19. We present a middle-aged gentleman with COVID-19 who developed bilateral basal ganglia ischemia. Such cases highlight the atypical neurologic sequelae of COVID-19, likely secondary to the associated prothrombotic state.

\section{Case presentation}

A 64-year-old Asian (Pakistani) diabetic and hypertensive gentleman initially presented with fever, cough, and progressive shortness of breath for 3 days. Prior to this presentation, the patient was on a combination of metformin-sitagliptin $1000 \mathrm{mg} / 50 \mathrm{mg}$ twice daily per oral (PO), atorvastatin $40 \mathrm{mg}$ once daily, and valsartanhydrochlorothiazide $160 \mathrm{mg} / 25 \mathrm{mg}$ daily PO. Patient was a never smoker and not an alcohol user. Patient was original author(s) and the source, provide a link to the Creative Commons licence, and indicate if changes were made. The images or other third party material in this article are included in the article's Creative Commons licence, unless indicated otherwise in a credit line to the material. If material is not included in the article's Creative Commons licence and your intended use is not permitted by statutory regulation or exceeds the permitted use, you will need to obtain permission directly from the copyright holder. To view a copy of this licence, visit http://creativecommons.org/licenses/by/4.0/. The Creative Commons Public Domain Dedication waiver (http://creativeco mmons.org/publicdomain/zero/1.0/) applies to the data made available in this article, unless otherwise stated in a credit line to the data. 
married and had two healthy kids. He was an accountant by profession. There was no personal or family history of malignancy, venous thromboembolism (VTE), or bleeding or clotting disorder. On presentation to the hospital, his blood pressure was 110/70 $\mathrm{mmHg}$, pulse rate was $100 \mathrm{bpm}$, respiratory rate was $23 / \mathrm{min}$, and oxygen saturation was $89 \%$ on room air. On examination, the patient had coarse crackles in bilateral lower lung fields, which did not change character with cough. Neurological examination was negative for meningeal signs and the Glasgow Coma Scale (GCS) was 15/15. The rest of the physical examination was unremarkable. A chest X-ray (CXR) demonstrated bilateral diffuse heterogeneous infiltrates, more pronounced on the right side. Due to high clinical suspicion, a nasopharyngeal swab was collected for SARS-CoV-2 Reverse transcription Polymerase Chain Reaction (RT PCR), which was positive, confirming COVID-19.

A high-resolution computed tomography (HRCT) of the chest showed multifocal, multilobar groundglass opacities in central and peripheral locations, more pronounced in middle and lower lobes, with septal thickening, giving a classical crazy paving appearance. Radiological Society of North America (RSNA) guidelines were used to calculate disease burden based on HRCT, and the score was 21/40 (severe disease burden) [4]. During the hospital stay, the patient was admitted to the COVID-19 isolation unit, where he received moxifloxacin, piperacillin/tazobactam, enoxaparin, and dexamethasone, based on the local COVID-19 treatment protocol at that time.

On day three of his hospital stay, the patient developed bilateral lower limb pain without any erythema, change in color, or change in the size of his lower limbs. An arterial and venous Doppler ultrasound was negative for occlusion or deep venous thrombosis. On day four, the patient was noted to have developed confusion and decreased level of consciousness. The GCS dropped from $15 / 15$ to $10 / 15$. The patient was emergently sedated, intubated, and mechanically ventilated to protect the airway.

An urgent non-contrast computed tomography (NCCT) of the brain (Fig. 1) revealed accentuated hypodensities in the left basal ganglia (involving caudate nucleus, lentiform nucleus, and anterior limb of internal capsule), with mass effect on the ipsilateral frontal horn. Another smaller hypodensity in the right caudate nucleus was also seen. With a diagnosis of ischemic stroke, the patient received aspirin and continued to receive statin and antihypertensives. However, thrombolysis was not considered as the exact time of onset of symptoms was not documented, and the patient had well-developed ischemic changes on the NCCT, signifying being past the thrombolytic period.

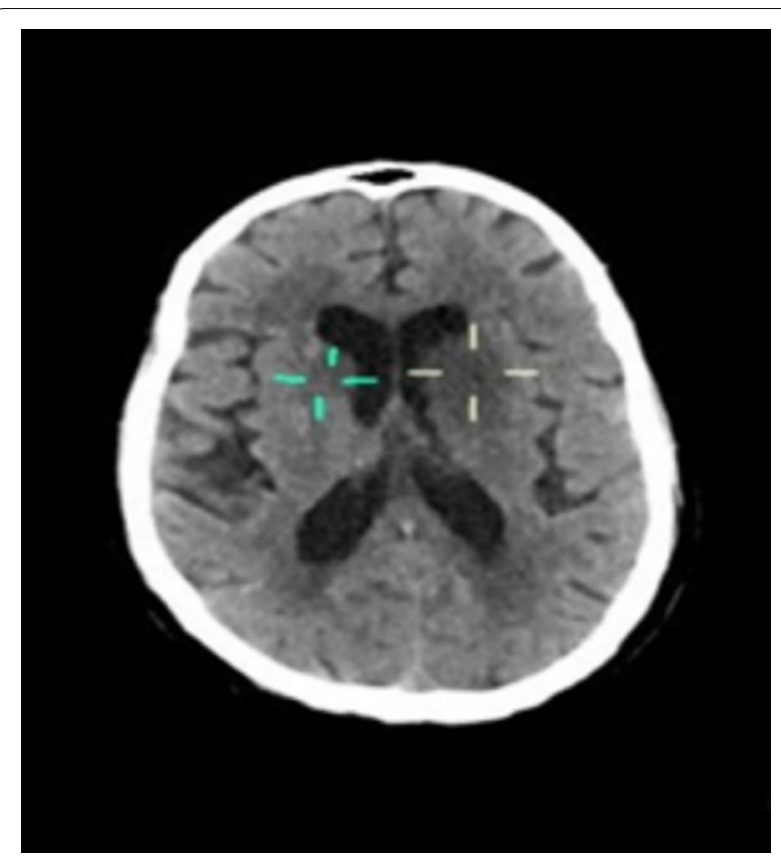

Fig. 1 Non-contrast computed tomography (NCCT) of the brain showing accentuated hypodensities in left basal ganglia (involving caudate nucleus, lentiform nucleus, and anterior limb of internal capsule) and a smaller hypodensity in the right caudate nucleus

Over the next few days, the patient received care in the intensive care unit, but his general condition deteriorated, with increasing oxygen requirements. On day 27 of the hospital stay, the patient developed cardiac arrest. Cardiopulmonary resuscitation was unsuccessful, and he passed away. Autopsy was declined by the family and, hence, could not be done.

\section{Discussion}

Our case describes a gentleman with severe COVID-19 pneumonia-associated bilateral basal ganglia hemorrhage. The incidence of bilateral basal ganglia ischemia during coronavirus infection is rare. A literature search performed on PubMed on 07 June 2021 using the Boolean operator strategy of "(basal ganglia) AND (ischemia) AND (COVID-19)" showed four results. The screening of abstracts revealed two cases by Matos et al. and Kulick-Soper et al. reporting basal ganglia ischemia $[15,16]$. Matos et al. attributed the stroke to vasculopathy and Kulick-Soper et al. attributed the ischemia to possible hypoxic-ischemic injury. The clinical and radiological features of both studies are listed in Table 1. The common feature is presence of altered mental status. However, unlike other cases, paresthesia, apathy, or movement abnormalities were not present.

The increased risk of ischemic cerebrovascular complications associated with COVID-19 is an emerging 
Table 1 Clinical features of ischemia of basal ganglia reported in the literature

\begin{tabular}{|c|c|c|c|c|}
\hline Author & Patient's age & Initial presentation & Neurological manifestations & CT findings \\
\hline Matos et al. & 42 years & $\begin{array}{l}\text { Fever, dry cough, myalgia, asthenia, } \\
\text { and hyposmia }\end{array}$ & $\begin{array}{l}\text { Altered mental status, slowness of } \\
\text { movements, and apathy }\end{array}$ & $\begin{array}{l}\text { Multiple hypodense lesions involving } \\
\text { the white matter, basal ganglia, and } \\
\text { thalamus }\end{array}$ \\
\hline Kulick-Soper et al. & 52 years & $\begin{array}{l}\text { Bilateral hand paresthesia followed } \\
\text { by fever, cough, dyspnea, headache, } \\
\text { and confusion }\end{array}$ & $\begin{array}{l}\text { Bilateral hand paresthesia and } \\
\text { confusion }\end{array}$ & $\begin{array}{l}\text { Symmetric hypoattenuation in } \\
\text { the bilateral globus pallidus with } \\
\text { surrounding small foci of hyperat- } \\
\text { tenuation }\end{array}$ \\
\hline
\end{tabular}

concern. As the COVID-19 pandemic has progressed, there has been a wide array of COVID-19-related neurologic manifestations, including encephalopathy, encephalitis, stroke, and Guillain-Barre syndrome [5]. COVID-19 has been linked to the hypercoagulable and prothrombotic state implicated in ischemic stroke [6]. The pathophysiology of COVID-19 helps explain the neurovascular effects of the disease. SARS-CoV-2, upon entry into the human body, binds the angiotensin-converting enzyme 2 (ACE-2) receptor, which is expressed on pulmonary type 2 pneumocytes, cardiac myocytes, and vascular endothelial cells [7]. Vascular endothelial cells are critical to the regulation of vascular permeability, maintaining hemostasis, and regulating hemolysis [8]. This explains their role in COVID-19 vasculopathy and thrombosis. In particular, SARS-CoV-2 releases interleukin-1 (IL-1), interferon-gamma, and tumor necrosis factor (TNF)-alpha, which not only leads to increased vascular permeability and endothelial injury, but also to increased platelet activation factor and inhibition of thrombomodulin, leading to thrombosis, as suggested by Shams et al. [9]. In patients with COVID19, native arterial occlusions are observed in both younger and older individuals, and more often in males than females in the general population [10].

The basal ganglia and thalamus are paired deep gray matter structures affected by various conditions, including systemic or metabolic diseases, degenerative vascular disorders, and infections [11]. Basal ganglia infarction is a type of cerebral infarct with unique clinical manifestations. Old age, diabetes, and hypertension are considered risk factors for cerebral ischemic lesions [12]. In an observational study on COVID-19 patients with neurological symptoms, about $5.5 \%$ of the patients were found to have basal ganglia lesions [13]. COVID19 is postulated to have neuroinvasive potential. In addition, the raised inflammatory markers may indicate a hyperinflammatory state, which may play a role in cerebral ischemia [14].

Our study has certain limitations. First, we were unable to investigate which underlying diseases significantly increase the relative risk of presenting with neuroinflammation and cerebrovascular disorders. Second, due to clinical circumstances, we were unable to obtain the magnetic resonance imaging for the patient. Further studies are required to fully elucidate the association between COVID-19-associated basal ganglia ischemia and the underlying pathophysiology. This case further signifies the importance of neuroimaging in the effective management of patients who present with an altered mental status and neurological signs during their COVID-19 illness.

\section{Conclusion}

COVID-19-associated basal ganglia ischemia may be multifactorial secondary to the prothrombotic state, hypoxic-ischemic injury, or vasculitis. Therefore, understanding the pathophysiology of basal ganglia involvement in COVID-19 and utilizing neuroimaging tools is vital in managing the neurological sequelae of SARS-CoV-2.

\section{Abbreviations}

COVID-19: Coronavirus disease 2019; SARS-CoV-2: Severe acute respiratory syndrome coronavirus 2; RT-PCR: Reverse transcription-polymerase chain reaction; HRCT: High-resolution computed tomography; RSNA: Radiological Society of North America; NCCT: Non-contrast computed tomography.

\section{Acknowledgements}

Not applicable.

\section{Authors' contributions}

KKB conceived and designed the study. KKB and MJT were responsible for data collection and acquisition of data. KKB, ARS, MJT, IU, and ZY analyzed and/or interpreted the data. ZY and HM performed the literature review. ARS, $H M$, and KKB wrote the initial manuscript. ZY, IU, and HM critically revised the manuscript. All authors have read and approved the final manuscript.

\section{Funding}

This study received no external funding.

Availability of data and materials Not applicable. 


\section{Declarations}

\section{Ethics approval and consent to participate}

Written informed consent for participation and publication was sought from the patient as per hospital protocol. Ethical approval was also obtained from the institutional review board.

\section{Consent for publication}

Written informed consent was obtained from the patient for publication of this case report and any accompanying images. A copy of the written consent is available for review by the Editor-in-Chief of this journal.

\section{Competing interests}

The authors declare that they do not have any competing interests.

\section{Author details}

'Shifa International Hospital, Islamabad, Pakistan. ${ }^{2}$ POF Hospital, Wah Cantt, Rawalpindi, Pakistan. ${ }^{3}$ Lahore General Hospital, Lahore 54000, Pakistan. ${ }^{4}$ Nishtar Medical University and Hospital, Multan, Pakistan. ${ }^{5}$ Kabir Medical College, Gandhara University, Peshawar, Pakistan. ${ }^{6}$ Hamad Medical Corporation, Doha, Qatar

Received: 1 July 2021 Accepted: 21 October 2021

Published online: 22 November 2021

\section{References}

1. Cascella M, Rajnik M, Aleem A, Dulebohn SC, Di Napoli R. Features, evaluation, and treatment of coronavirus (COVID-19). 2021. In: StatPearls. Treasure island (FL): StatPearls Publishing; 2021.

2. Coopersmith CM, Antonelli M, Bauer SR, Deutschman CS, Evans LE, Ferrer R, Hellman J, Jog S, Kesecioglu J, Kissoon N, Martin-Loeches I, Nunnally ME, Prescott HC, Rhodes A, Talmor D, Tissieres P, De Backer D. The surviving sepsis campaign: research priorities for coronavirus disease 2019 in critical illness. Crit Care Med. 2021;49(4):598-622.

3. Katz JM, Libman RB, Wang JJ, Sanelli P, Filippi CG, Gribko M, Pacia SV Kuzniecky RI, Najjar S, Azhar S. Cerebrovascular complications of COVID19. Stroke. 2020;51(9):e227-31

4. Yang R, Li X, Liu H, Zhen Y, Zhang X, Xiong Q, Luo Y, Gao C, Zeng W. Chest CT severity score: an imaging tool for assessing severe COVID-19. Radiol Cardiothorac Imaging. 2020;2(2): e200047.

5. Mao L, Jin H, Wang M, Hu Y, Chen S, He Q, Chang J, Hong C, Zhou Y, Wang D, Miao X, Li Y, Hu B. Neurologic manifestations of hospitalized patients with coronavirus disease 2019 in Wuhan, China. JAMA Neurol. 2020;77(6):683-90.

6. Kichloo A, Dettloff K, Aljadah M, Albosta M, Jamal S, Singh J, Wani F, Kumar A, Vallabhaneni S, Khan MZ. COVID-19 and hypercoagulability: a review. Clin Appl Thromb/Hemost. 2020;26:1076029620962853.

7. Yuki K, Fujiogi M, Koutsogiannaki S. COVID-19 pathophysiology: a review. Clin Immunol. 2020;215: 108427.

8. McGonagle D, O'Donnell JS, Sharif K, Emery P, Bridgewood C. Immune mechanisms of pulmonary intravascular coagulopathy in COVID-19 pneumonia. Lancet Rheumatol. 2020;2(7):e437-45.

9. Shams A, Ata F, Mushtaq K, Munir W, Yousaf Z. Coronary thrombosis in a young male with COVID-19. IDCases. 2020;21: e00923. https://doi.org/10. 1016/j.idcr.2020.e00923.

10. Bellosta R, Luzzani L, Natalini G, Pegorer MA, Attisani L, Cossu LG, Ferrandina C, Fossati A, Conti E, Bush RL, Piffaretti G. Acute limb ischemia in patients with COVID-19 pneumonia. J Vasc Surg. 2020;72(6):1864-72.

11. Hegde AN, Mohan S, Lath N, Lim CC. Differential diagnosis for bilateral abnormalities of the basal ganglia and thalamus. Radiographics. 2011;31(1):5-30.

12. Lee SC, Park SJ, Ki HK, Gwon HC, Chung CS, Byun HS, Shin KJ, Shin MH, Lee WR. Prevalence and risk factors of silent cerebral infarction in apparently normal adults. Hypertension. 2000;36(1):73-7.

13. Chougar L, Shor N, Weiss N, Galanaud D, Leclercq D, Mathon B, Belkacem S, Ströer S, Burrel S, Boutolleau D, Demoule A, Rosso C, Delorme C, Seilhean D, Dormont D, Morawiec E, Raux M, Demeret S, Gerber S, Trunet $\mathrm{S}$, et al., CoCo Neurosciences Study Group. Retrospective observational study of brain MRI findings in patients with acute SARS-CoV-2 infection and neurologic manifestations. Radiology. 297(3): E313-E323.

14. TunÇ A, ÜnlÜbaş Y, Alemdar M, AkyÜz E. Coexistence of COVID-19 and acute ischemic stroke report of four cases. J Clin Neurosci. 2020;77:227-9.

15. Matos AR, Quintas-Neves M, Oliveira Al, Dias L, Marques S, Carvalho R, Alves JN. COVID-19 associated central nervous system vasculopathy. Can J Neurol Sci. 2021;48(1):139-40.

16. Kulick-Soper CV, McKee JL, Wolf RL, Mohan S, Stein JM, Masur JH, Lazor JW, Dunlap DG, McGinniss JE, David MZ, England RN, Rothstein A, Gelfand MA, Cucchiara BL, Davis KA. Pearls and oysters: bilateral globus pallidus lesions in a patient with COVID-19. Neurology. 2020;95(10):454-7.

\section{Publisher's Note}

Springer Nature remains neutral with regard to jurisdictional claims in published maps and institutional affiliations.
Ready to submit your research? Choose BMC and benefit from:

- fast, convenient online submission

- thorough peer review by experienced researchers in your field

- rapid publication on acceptance

- support for research data, including large and complex data types

- gold Open Access which fosters wider collaboration and increased citations

- maximum visibility for your research: over 100M website views per year

At BMC, research is always in progress.

Learn more biomedcentral.com/submissions 